\title{
Role of Direct Aging and Solution Treatment on Hardness, Microstructure and Residual Stress of the A357 (AlSi7Mg0.6) Alloy Produced by Powder Bed Fusion
}

\author{
LAVINIA TONELLI, ERICA LIVERANI, ALESSANDRO MORRI, \\ and LORELLA CESCHINI
}

\begin{abstract}
Applying additive manufacturing (AM) technologies to the fabrication of aluminum automotive components, with an optimized design, may result in improved vehicle light weighting. However, the post-process heat treatment of such alloys has to be customized for the particular AM microstructure. The present study is aimed at investigating the effect of different heat treatments on the microstructure, hardness and residual stress of the A357 (AlSi7Mg0.6) heat-treatable alloy produced by laser-based powder bed fusion (LPBF, also known as selective laser melting). There are two major issues to be addressed: (1) relieving the internal residual stress resulting from the process and (2) strengthening the alloy with a customized heat treatment. Therefore, stress-relief annealing treatment, direct aging of the as-built alloy and a redesigned T6 treatment (consisting of a shortened high-temperature solution treatment followed by artificial aging) were examined. Comparable hardness values were reached in the LPBF alloy with optimized direct aging and T6 treatments, but complete relief of the residual stress was obtained only with T6. Microstructural analyses also suggested that, because of the supersaturated solid solution, different phenomena were involved in direct aging and T6 treatment.
\end{abstract}

https://doi.org/10.1007/s11663-021-02179-6

(C) The Author(s) 2021

\section{INTRODUCTION}

VEHICLE light weighting and engine downsizing are two of the main strategies pursued to meet strict regulations on pollutant and greenhouse gas emissions. For this reason, aluminum alloys are one of the most widely used structural materials in the transportation field. Their high strength-to-weight ratio, in fact, can bring a significant weight reduction with consequent improvement of fuel efficiency and decrease in energy consumption and emissions. ${ }^{[1,2]}$ Structural aluminum parts are obtained by conventional processing routes, including both plastic deformation and casting, because

LAVINIA TONELLI, ALESSANDRO MORRI, and LORELLA CESCHINI are with the Department of Industrial Engineering (DIN), Alma Mater Studiorum-University of Bologna, Viale Risorgimento 4, 40136 Bologna, Italy. Contact e-mail: lavinia.tonelli2@unibo.it ERICA LIVERANI is with the Interdepartmental Center for Industrial Research-Advanced Applications in Mechanical Engineering and Materials Technology (CIRI-MAM), Alma Mater Studiorum-University of Bologna, Bologna, Italy.

Manuscript submitted December 3, 2020; accepted April 6, 2021.

Article published online May 19, 2021. of the processing versatility typical of aluminum alloys. However, conventional manufacturing is restricted to a limited degree of design complexity and customization. Therefore, the innovative additive manufacturing (AM) technologies, in particular, the one termed laser-based powder bed fusion (LPBF), can be positively used for the fabrication of complex lightweight Al parts. LPBF consists of the localized melting of subsequent layers of fine metallic powder (powder bed) by means of a computer-driven focused laser beam. ${ }^{[3]}$ Due to its layer-wise approach and high accuracy, which the focused beam can guarantee, a complex and customized design can be produced and features such as inner cavities, conformal cooling channels and even lattice structures can be realized for improved weight reduction. Not all aluminum alloys can be processed with this technology since Al alloys with a large solidification range, like, for example, $\mathrm{Al}-\mathrm{Cu}$ or $\mathrm{Al}-\mathrm{Zn}$ alloys, are prone to hot cracking. ${ }^{[4]} \mathrm{Al}-\mathrm{Si}$ cast alloys, on the other hand, with proper Si content, are characterized by high fluidity and a narrow solidification range that increases castability by reducing the hot cracking and shrinkage tendency. ${ }^{[5]}$ Therefore, most of the research has been focused on LPBF of eutectic AlSi12 and near-eutectic $\mathrm{AlSi} 10 \mathrm{Mg}$ alloys, while more limited data are available 
on AlSi7Mg hypoeutectic alloys. ${ }^{[4]}$ The latter (such as A356 and A357, with 0.3 and 0.6 wt pet $\mathrm{Mg}$, respectively) are the most widely used Al casting alloys for power train system components such as engine blocks. ${ }^{[6,7]}$ The presence of $\mathrm{Mg}$ allows the application of the T6 treatment, meaning that significant strengthening of the alloy is achieved by precipitation of fine coherent intermetallic particles (i.e., $\beta^{\prime \prime}-\mathrm{Mg}_{2} \mathrm{Si}$ ) during the aging treatment. ${ }^{[8]}$ Strengthening of the heat-treatable alloys depends on $\mathrm{Mg}$ content and, in particular, on the $\mathrm{Mg}: \mathrm{Si}$ ratio, which is particularly advantageous for the AlSi7Mg0.6 (A357) alloy. ${ }^{[9]}$ The conventional T6 heat treatment for this alloy consists of high-temperature solutionizing $\left(540{ }^{\circ} \mathrm{C} \times 8 \mathrm{~h}\right)$ followed by quenching in warm water and subsequent artificial aging $\left(165^{\circ} \mathrm{C} \times\right.$ 6-12 hours). ${ }^{[10]}$ However, heat treatment for LPBF parts has to be redesigned because of the different microstructures produced by the process compared to those induced by conventional casting technologies, such as sand or permanent mold casting. The microstructure of conventional castings are typically characterized by $\alpha-\mathrm{Al}$ dendrites, surrounded by the eutectic structure, with secondary dendrite arm spacing (SDAS) values in the range 60 to $20 \mu \mathrm{m}$, for sand and permanent mold castings, respectively. ${ }^{[7,8,11]}$ Eutectic silicon can be fibrous or acicular, depending on the chemical modification of the molten alloy. Coarse intermetallic particles, formed during solidification, should be also observed. LPBF instead leads to a typical hierarchical microstructure characterized at low magnification by epitaxial grains along the building direction (BD) and at high magnification by micrometric melt pools and submicrometric primary Al cells surrounded by a network of fine eutectic Si. In conventional cast alloy, the first step of the T6 heat treatment, i.e., high temperature solution treatment, close to the solidus curve, aims to bring most of the alloy elements into solid solution by dissolution of the coarser particles formed during solidification. The following quenching treatment allows the formation of a supersaturated metastable solid solution, whose degree of supersaturation influences the final alloy hardness. Strengthening, in fact, occurs during the final artificial aging by the precipitation of coherent and semi-coherent nanometric particles from the supersaturated solid solution.

It is widely recognized that, in metals components produced by LPBF, significant strengthening occurs in the as-built alloys by grain refinement induced by the process. Therefore, holding at the solution temperature for a long time can result in a detrimental coarsening of the as-built microstructure, as the first studies reported. ${ }^{[12]}$ Moreover, because of the very fast solidification rate, the final LPBF microstructure is a supersaturated, metastable solid solution with solubility of alloying elements extended up to $5.4 \mathrm{wt}$ pct in case of $\mathrm{Si}$ in $\mathrm{Al}$ matrix for $\mathrm{AlSi} 7 \mathrm{Mg} .{ }^{[12]}$ These conditions potentially make the LPBF Al alloy suitable for a direct aging treatment, thus avoiding the coarsening effect of high-temperature solution treatment. Based on the above, studies aimed at optimizing the heat treatment of AlSi7Mg samples produced by LPBF are needed. Several scientific papers, in fact, were recently focused on heat treatments of LPBF AlSi7Mg0.6, and the current state of the art on this topic can be summarized as follows: (1) conventional T6 treatment, ${ }^{[13,14]}$ (2) T6 treatment with a shortened solution treatment $(0.25,1$, 2 hours), ${ }^{[14-16]}$ (3) direct aging from the as-built condition at the conventional aging temperature of 160 to $165^{\circ} \mathrm{C},{ }^{[14,15,17]}$ and (4) stress-relieving treatment performed at $300{ }^{\circ} \mathrm{C} \times 2$ to 3 hours. ${ }^{[13,16,18,19]}$ The scope of direct aging and T6 treatment is to induce alloy strengthening. On the other hand, stress relieving is usually recommended to avoid deformations of the as-printed parts when separated from the building platform. Residual stress is, indeed, one of the major concerns regarding LPBF components, especially in case of aluminum alloys given their high thermal conductivity and expansion. ${ }^{[4]}$ Unfortunately, literature data showed that the common stress-relieving treatment can be detrimental for hardness and tensile properties. ${ }^{[13,16,18,19]}$ It is worth mentioning that a systematic study comparing all the above-discussed treatment conditions for the $\mathrm{AlSi} 7 \mathrm{Mg} 0.6$ (A357) alloy, one of the most widely used casting Al alloys, is currently lacking. Moreover, a common practice to reduce residual stress and cracking is pre-heating the building platform at a temperature between $100{ }^{\circ} \mathrm{C}$ and $200{ }^{\circ} \mathrm{C}$ for the entire process, as adopted by many of the mentioned experimental works. ${ }^{[15,16,18,21]}$ Platform pre-heating can however induce in situ precipitation of second phases, thus leading to artificial aging or even over-aging of the alloy during the process itself, as demonstrated by some researchers. ${ }^{[16,20]}$ In situ aging of the alloy can affect any subsequent heat treatment, and, more importantly, it strictly depends on manufacturing time, which can significantly vary from one component to another.

Based on the above, the present study is aimed at systematically investigating the effect of different heat treatments on the microstructure, hardness, and residual stress of the A357 alloy produced by LPBF with no platform pre-heating. Aging curves at four different temperatures have been evaluated starting from both as-built and solution-treated samples, thus considering both direct aging and T6 treatment to define the optimized treatment conditions for LPBF A357. A short solution treatment (10 minutes) was chosen to limit the microstructural coarsening and the increase in the porosity content evidenced by literature works. ${ }^{[12,15,16]}$ With the aim to assess the effect of the investigated treatments on residual stress, the results have also been compared to the stress-relieving treatment, and Raman spectroscopy was used to compare the residual stress of the investigated samples. As a reference, the same analyses were also carried out on the conventional sand-cast A357 alloy. 


\section{EXPERIMENTAL PROCEDURE}

\section{A. Material and LPBF Process}

AlSi7Mg0.6 samples (designated as A357 according to the International Alloy Designation System and EN-AC42200 according to the EN1780 numerical system) were produced by LPBF in the form of block with a $10 \times 10 \mathrm{~mm}^{2}$ square base and $20 \mathrm{~mm}$ height. Gas atomized powder was supplied by the former LPW (currently, LPW Carpenter Additive, Carpenter Technology Corporation, USA). The powder, which has been fully characterized in a previous work, ${ }^{[21]}$ had an almost spherical morphology a size range of 5 to $75 \mu \mathrm{m}$ for approximately $96 \mathrm{pct}$ of the particles. Before the process, powder was subjected to a drying pre-treatment at $60{ }^{\circ} \mathrm{C}$ for 3 hours. A SISMA MySint $100 \mathrm{RM}$ metal 3D printer with a fiber laser source with a nominal spot diameter of $55 \mu \mathrm{m}$ was used for sample fabrication on an aluminum platform without pre-heating. The process was carried out in a nitrogen environment with a low oxygen content $(0.1 \mathrm{vol} \mathrm{pct})$ and adopting the process parameters summarized in Table I. A $3 \times 3 \mathrm{~mm}^{2}$ roto-translating chessboard pattern was selected, with a rotation angle of $45 \mathrm{deg}$ and a $3 \mathrm{~mm}$ translation on the $x$ and $y$ axis between successive layers. All samples were produced in a single batch, with a vertical building direction, to assure a common in-process thermal cycle. After the building process, samples were stored at $-20{ }^{\circ} \mathrm{C}$ until heat treatments and analyses to avoid the natural pre-aging that can affect the final alloy hardness. ${ }^{22]}$

Conventional sand cast samples, used as reference, were extracted from engine blocks. Chemical compositions of cast and LPBF samples were determined by Glow Discharge Optical Emission Spectroscopy (GDOES, GDA-650 Spectrum Analytik GmbH), and the results are reported in Table II, compared to the nominal composition of feedstock powder. No deviations from the requirements given by the EN 1706 standard for the A1Si7Mg0.6 alloy or appreciable differences between samples were evidenced. Furthermore, in case of LPBF alloy, no vaporization of low-melting alloy elements (e.g., $\mathrm{Mg}$ ) was shown.

\section{B. Heat Treatments}

LPBF samples were subjected to artificial aging, stress-relieving and solution treatments. The investigated heat treatment conditions, in terms of temperature and holding time, are reported in Table III.

It is widely recognized that aging time and temperatures need to be optimized for a specific $\mathrm{Al}$ alloy to obtain a required minimum strength level in a commer- cially reasonable period of time. For this reason, aging curves were evaluated for LPBF alloy subjected to artificial aging (AA) by measuring the $\mathrm{HV}_{1}$ hardness at fixed times for the given temperature, and compared with those of conventional cast samples. Four temperatures were investigated in steps of $20^{\circ} \mathrm{C}: 150{ }^{\circ} \mathrm{C}, 170$ ${ }^{\circ} \mathrm{C}, 190{ }^{\circ} \mathrm{C}$ and $210{ }^{\circ} \mathrm{C}$ for a total holding time of 28 hours. Aging curves display hardness evolution as a function of holding time at a specific aging temperature, thus allowing the identification of the peak aging condition where the heat-treated alloy exhibits the highest hardness. Before artificial aging, cast samples were subjected to the conventional long-term (12 hours) solution treatment (ST) followed by water quenching (WQ). LPBF samples were instead subjected to artificial aging both in the as-built state and after a short-term (10 minutes) ST followed by WQ. ST in case of LPBF alloy was set at 10 minutes based on both the literature results and microstructural analyses. In fact, as previously discussed, the literature suggests ${ }^{[13,14]}$ that in case of LPBF a shortened ST (1 to 2 hours) is more appropriate than the conventional 8-hour treatment. In fact, as LPBF results in a supersaturated condition, a prolonged solution treatment induces undesired grain coarsening. A similar approach was already followed for high-pressure diecasting aluminum alloys, in which rapid ST was promoted to reduce blistering. ${ }^{[23,24]}$ In Figure 1, the microstructural analyses performed on LPBF samples after a 10, 30, and 60 minutes ST are compared. As will be discussed in detail in Section III-C, reporting the microstructural analyses, the 10-minute ST was sufficient to break up the Si network and to form globular particles, which were homogeneously dispersed in the Al matrix. By increasing the treatment time, particle coarsening occurred because of the diffusion processes. The average size of Si particles, evaluated by image analyses in terms of Feret's diameter, increased by prolonging the solution time from 10 to 30 and 60 minutes. More importantly, the number of particles in a $1 \mu \mathrm{m}^{2}$ area decreased with treatment time, suggesting a less homogeneous dispersion. For these reasons, ST was set at 10 minutes.

Cast and LPBF samples that underwent $\mathrm{ST}+\mathrm{WQ}+\mathrm{AA}$ are identified as T6, while LPBF samples that were submitted to direct artificial aging from the as-built condition are identified by AA.

As a reference for relief of residual stress, the assessment of stress-relieving (SR) treatment usually applied to aluminum LPBF parts was also performed at three different temperatures $\left(100{ }^{\circ} \mathrm{C}, 200{ }^{\circ} \mathrm{C}\right.$, and 300 ${ }^{\circ} \mathrm{C}$ ) for a fixed soaking time of 2 hours. Hardness $\mathrm{HV}_{1}$ measurements were carried out on SR samples after the treatment.

Table I. Process Parameters Adopted for LPBF A357 Sample Production

\begin{tabular}{lcccc}
\hline Power $(\mathrm{W})$ & Layer Thickness $(\mathrm{mm})$ & Hatch Distance $(\mathrm{mm})$ & Scanning Velocity $(\mathrm{mm} / \mathrm{s})$ & Shielding Gas \\
\hline 170 & 0.02 & 0.07 & 500 & $\mathrm{~N}_{2}$ \\
\hline
\end{tabular}


Table II. Chemical Compositions (Wt Pct) of Cast and LPBF A357 Samples Determined by GDOES Analyses Compared to the Nominal Composition of Powders Given by the Supplier

\begin{tabular}{|c|c|c|c|c|c|c|c|}
\hline \multirow{2}{*}{ Samples } & \multicolumn{7}{|c|}{ Element (Wt Pct) } \\
\hline & Al & $\mathrm{Si}$ & $\mathrm{Mg}$ & $\mathrm{Zn}$ & $\mathrm{Ti}$ & $\mathrm{Fe}$ & Other \\
\hline Cast & $\begin{array}{l}92.34 \\
\pm 0.19\end{array}$ & $\begin{array}{l}6.52 \\
\pm 0.27\end{array}$ & $\begin{array}{l}0.64 \\
\pm 0.05\end{array}$ & $\begin{array}{l}0.20 \\
\pm 0.01\end{array}$ & $\begin{array}{l}0.18 \\
\pm 0.01\end{array}$ & $\begin{array}{l}0.06 \\
\pm 0.01\end{array}$ & $\begin{array}{l}0.06 \\
-\end{array}$ \\
\hline LPBF & $\begin{array}{l}92.40 \\
\pm 0.19\end{array}$ & $\begin{array}{l}6.69 \\
\pm 0.13\end{array}$ & $\begin{array}{l}0.57 \\
\pm 0.02\end{array}$ & $\begin{array}{l}0.05 \\
\pm 0.01\end{array}$ & $\begin{array}{l}0.15 \\
\pm 0.01\end{array}$ & $\begin{array}{l}0.09 \\
\pm 0.01\end{array}$ & $\begin{array}{l}0.07 \\
-\end{array}$ \\
\hline Powder & bal. & 6.90 & 0.55 & $<0.01$ & 0.09 & 0.09 & $<0.15$ \\
\hline
\end{tabular}

Table III. Investigated Heat Treatments: Designations and Conditions in Terms of Temperature and Holding Time

\begin{tabular}{|c|c|c|c|c|c|c|c|}
\hline \multirow{2}{*}{ Samples } & \multicolumn{2}{|c|}{ Stress Relieving (SR) } & \multicolumn{2}{|c|}{ Solution Treatment (ST) } & \multirow{2}{*}{ Quenching (WQ) } & \multicolumn{2}{|c|}{ Artificial Aging (AA) } \\
\hline & $T\left({ }^{\circ} \mathrm{C}\right)$ & $t(\mathrm{~h})$ & $T\left({ }^{\circ} \mathrm{C}\right)$ & $t(\mathrm{~h})$ & & $T\left({ }^{\circ} \mathrm{C}\right)$ & $t(\mathrm{~h})$ \\
\hline Cast T6 & - & - & 540 & 12 & warm water $\left(60^{\circ} \mathrm{C}\right)$ & $\begin{array}{l}150 \\
170 \\
190 \\
210\end{array}$ & $0-28$ \\
\hline LPBF T6 & - & - & 540 & 0.17 & warm water $\left(60^{\circ} \mathrm{C}\right)$ & $\begin{array}{l}150 \\
170 \\
190 \\
210\end{array}$ & $0-28$ \\
\hline LPBF AA & - & - & - & - & - & $\begin{array}{l}150 \\
170 \\
190 \\
210\end{array}$ & $0-28$ \\
\hline LPBF SR & $\begin{array}{l}100 \\
200 \\
300\end{array}$ & 2 & - & - & - & - & - \\
\hline
\end{tabular}

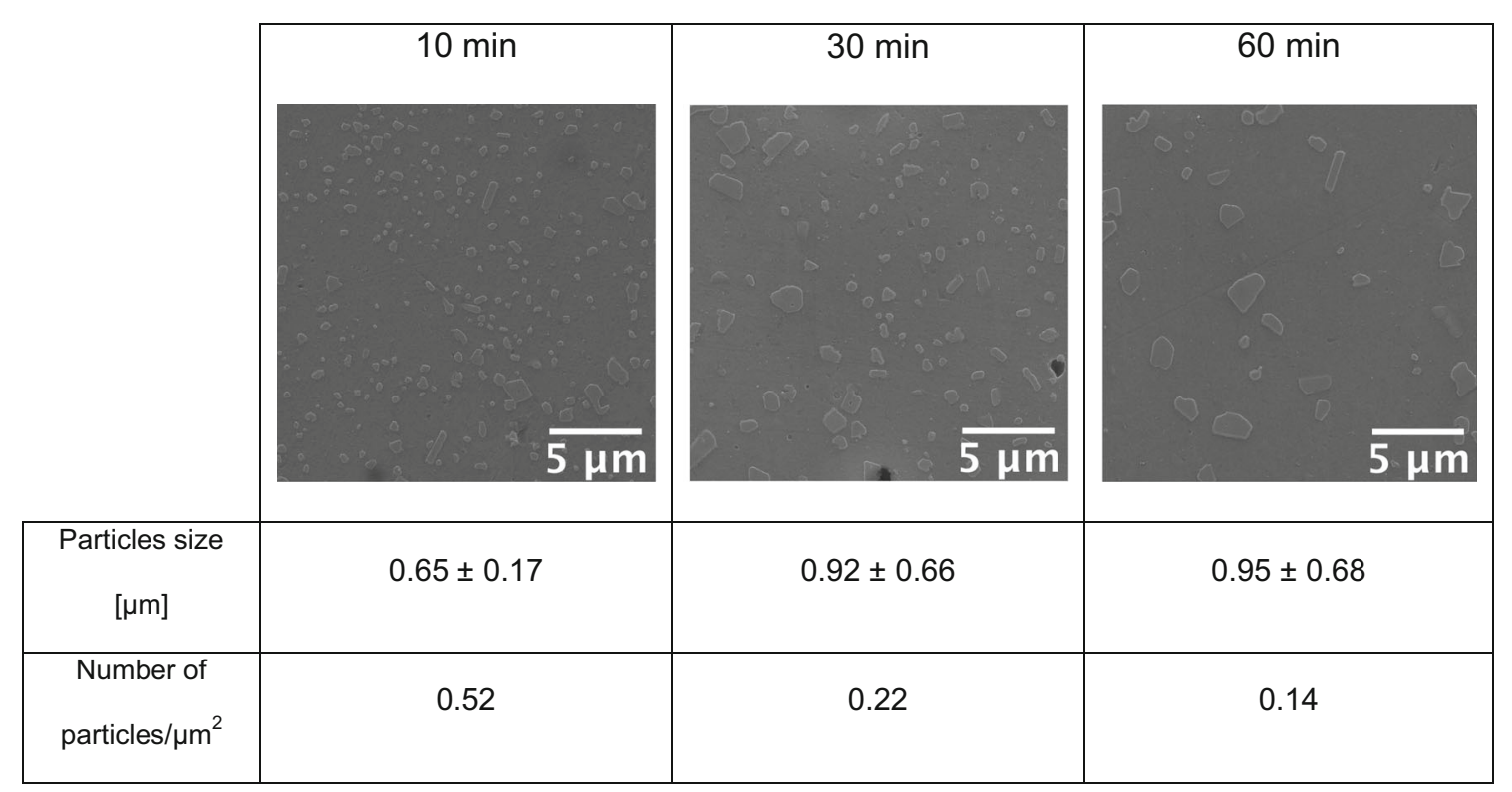

Fig. 1-Microstructural analyses of ST +WQ LPBF samples showing the effect of increasing solution treatment time from 10 to 30 and 60 min. 


\section{Microstructural Characterization}

As-built and heat-treated samples were subjected to a complete microstructural characterization performed by optical (OM, Reichert MEF3), scanning electron (SEM, Zeiss Evo 50), and field emission-gun scanning electron (FEG-SEM, Tescan Mira3) microscopes; the latter two were equipped with energy-dispersive X-ray spectroscopy (EDS). Before the analyses, samples were prepared following standard metallographic procedures $^{[25]}$ up to polishing with $1 \mu \mathrm{m}$ polycrystalline diamond suspension. Before the observation, samples were chemically etched with 20 -second immersion in Keller's reagent $\left(2.5 \mathrm{~mL} \mathrm{HNO}_{3}, 1.5 \mathrm{~mL} \mathrm{HCl}, 1.0 \mathrm{~mL}\right.$ $\mathrm{HF}$ and $95 \mathrm{~mL}$ distilled water) at room temperature.

Residual stress in untreated and heat-treated samples was evaluated by $\mu$ Raman spectroscopy by measuring the Raman shift of the Si peak on polished cross-sections, as already proposed by other researchers for the same alloy ${ }^{[12,19]}$ and as commonly used for Si-based products. ${ }^{[26-28]}$ At least five spectra per condition were randomly

LPBF as-built

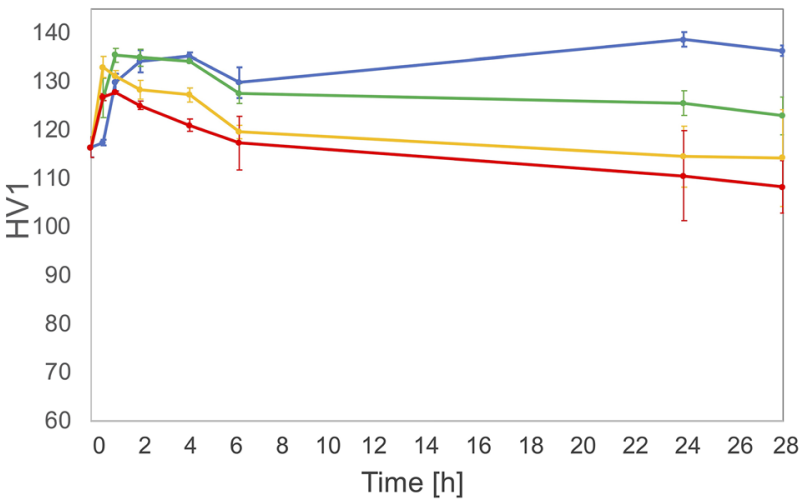

(a)

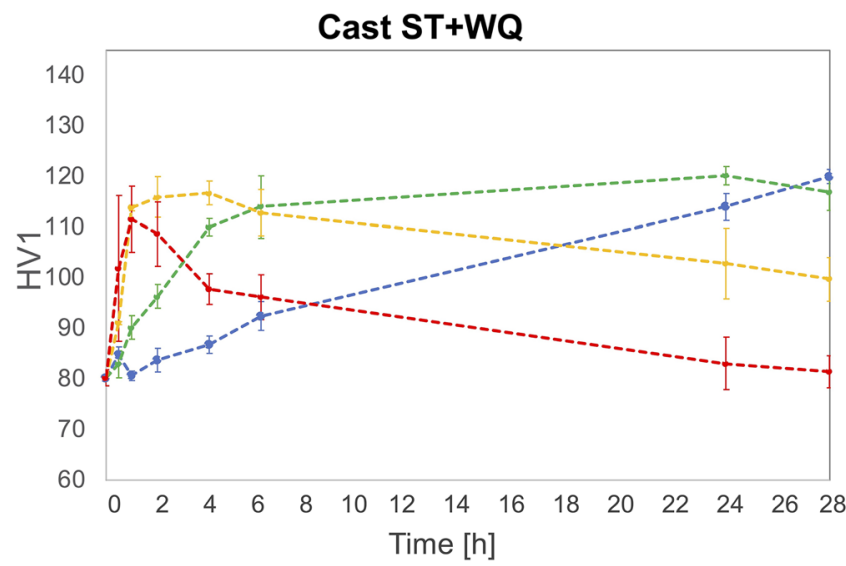

(c) acquired; each spectrum consisted of ten accumulations with 10-second dwell time in ambient condition. Spectra were recorded by means of a Renishaw InVia micro-spectrometer equipped with a Leica DMLM microscope using a $50 \mathrm{~mW} \mathrm{Ar}{ }^{+}$laser source (wavelength $514.5 \mathrm{~nm}$ ).

Thermal analyses were carried out using a differential thermal analyzer (DTA, Rheometric Scientific STA 1500) on LPBF as-built, LPBF ST + WQ, and cast ST + WQ alloys. Specimens of about $30 \mathrm{mg}$ mass were heated in the temperature range $30^{\circ} \mathrm{C}$ to $550{ }^{\circ} \mathrm{C}$ with a heating rate of $15^{\circ} \mathrm{C} \mathrm{min}{ }^{-1}$ under Ar atmosphere. DTA curves were then elaborated with RSI Orchestrator software to determine the onset and peak temperatures.

Phase composition was determined by X-ray diffraction (XRD, PANalytical Expert PRO with Xcelerator detector) with $\mathrm{Cu} \mathrm{K} \alpha(\lambda=0.15406 \mathrm{~nm})$ radiation. $\theta-2 \theta$ scans were carried out in the range 20 to 90 deg with $0.017 \mathrm{deg}$ step size and 10 seconds dwell time. XRD spectra were then processed with the Xpert Highscore Plus software for phase identification and peak analysis.

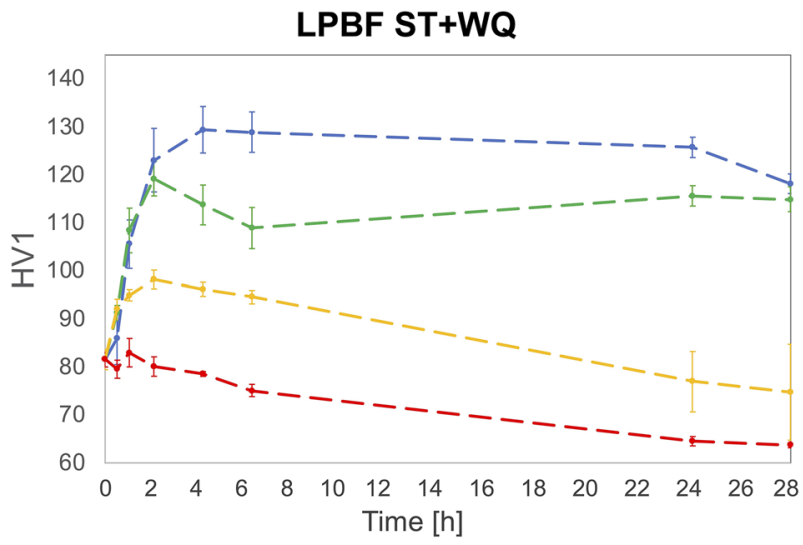

(b)

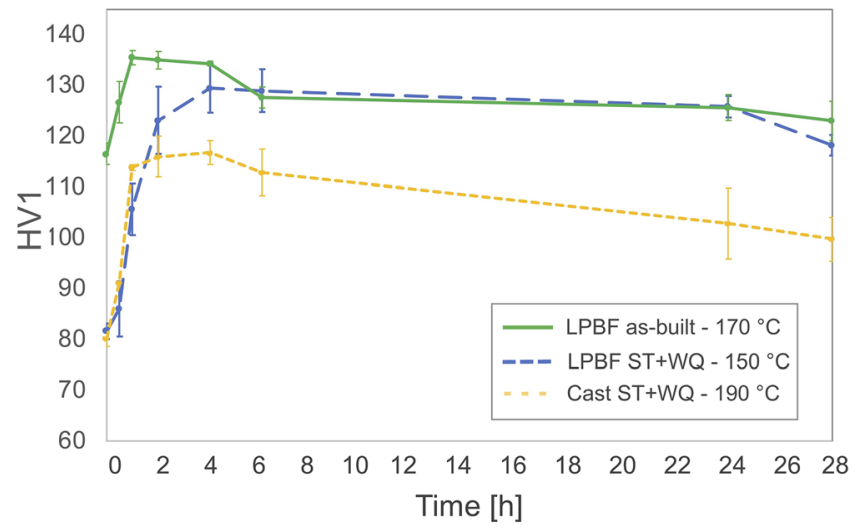

(d)

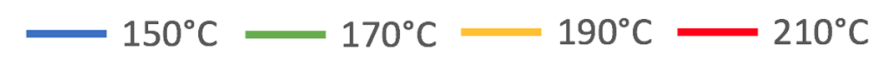

Fig. 2-Aging curves at different temperatures (in the range $150{ }^{\circ} \mathrm{C}$ to $210{ }^{\circ} \mathrm{C}$ ) for the A357 alloy: (a) LPBF as-built (continuous lines), (b) LPBF ST + WQ (long-dashed lines), (c) sand-cast ST + WQ (short-dashed lines), and (d) comparison of peak aging curves for all conditions. 


\section{RESULTS}

\section{A. Aging Curves}

The strengthening effect of aging treatment of the LPBF as-built, LPBF and cast solution-treated (ST) alloys has been assessed by drawing the aging curves, reported in Figure 2, by measuring the hardness evolution as a function of holding time at different aging temperatures.

In case of direct artificial aging, up to 3 hours soaking time, of LPBF as-built alloy (Figure 2(a)), all the investigated temperatures induced strengthening, with the peak-aging condition found at $170{ }^{\circ} \mathrm{C} \times 1$ hour, producing a $17 \mathrm{pct}$ hardness increase with respect to the as-built condition (from 117 to $136 \mathrm{HV}_{1}$ ). For longer holding time, the higher tested temperatures (in the range $170{ }^{\circ} \mathrm{C}$ to $210{ }^{\circ} \mathrm{C}$ ) induced softening of the alloy, probably because of over-aging caused by coarsening of strengthening intermetallics, while at the lower temperature of $150{ }^{\circ} \mathrm{C}$ a second hardness peak was found. However, since it corresponds to 24 hours soaking time, in view of preserving the time and cost-efficiency of the whole process, this condition was not further investigated. Regardless, it is worth mentioning that this a valuable result in case of a long-term process carried out on a pre-heated platform at the usual temperature of 150 ${ }^{\circ} \mathrm{C}$.

LPBF and conventional sand-cast A357 samples were also aged after conventional solution treatment and water quenching, and the corresponding aging curves are reported in Figures 2(b) and (c), respectively.

It should be noted that after solution treatment and water quenching, LPBF alloy (characterized by a lower starting hardness of about $80 \mathrm{HV}_{1}$ with respect to the as-built alloy) became more sensitive to aging temperature (Figure 2(b)). The highest tested temperature (210 ${ }^{\circ} \mathrm{C}$ ) led to a substantial hardness loss, while a short treatment (about 2 hours) at $190{ }^{\circ} \mathrm{C}$ induced a limited hardness increase (from 82 to $120 \mathrm{HV}_{1}$ ). A more significant strengthening was instead obtained with aging at $150{ }^{\circ} \mathrm{C}$ and $170{ }^{\circ} \mathrm{C}$, with an outstanding 60 pet raise in the hardness value after 4 hours at $150{ }^{\circ} \mathrm{C}$, which defined the peak-aging condition $\left(130 \mathrm{HV}_{1}\right)$.

In case of the conventional cast alloy (Figure 2(c)) the most favorable peak-aging condition was found with heating at $190{ }^{\circ} \mathrm{C} \times 4$ hours, which led to a $46 \mathrm{pct}$ increase in hardness compared to the solution-treated and water-quenched cast alloy (from 80 to $117 \mathrm{HV}_{1}$ ). As for the LPBF ST + WQ, also the cast ST + WQ alloy was quite sensitive to the aging temperatures. However, in case of the conventional cast alloy, the lowest temperatures $\left(150{ }^{\circ} \mathrm{C}\right.$ and $\left.170{ }^{\circ} \mathrm{C}\right)$ only induced a hardness increase for a long soaking time. In fact, a hardness value close to the peak-aged one was reached after 10 to 12 hours at the aging temperature of $170{ }^{\circ} \mathrm{C}$, as advised by the ASTM B917 standard, ${ }^{[10]}$ and after holding for $>$ 24 hours at $150{ }^{\circ} \mathrm{C}$. Aging at $210{ }^{\circ} \mathrm{C}$ instead led to a lower peak hardness at a shorter aging time, while the LPBF ST + WQ alloy aged at the same temperature displayed a noticeable softening. These differences are presumably ascribable to the different microstructural features between the cast and LPBF alloy, as will be

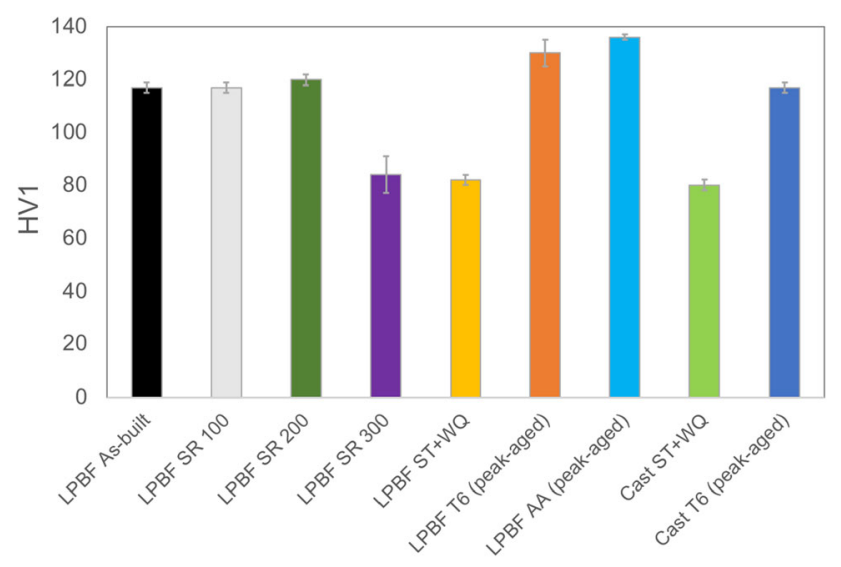

Fig. 3-Mean hardness values $\left(\mathrm{HV}_{1}\right)$ measured on as-built and heat-treated LPBF samples and heat-treated cast samples.

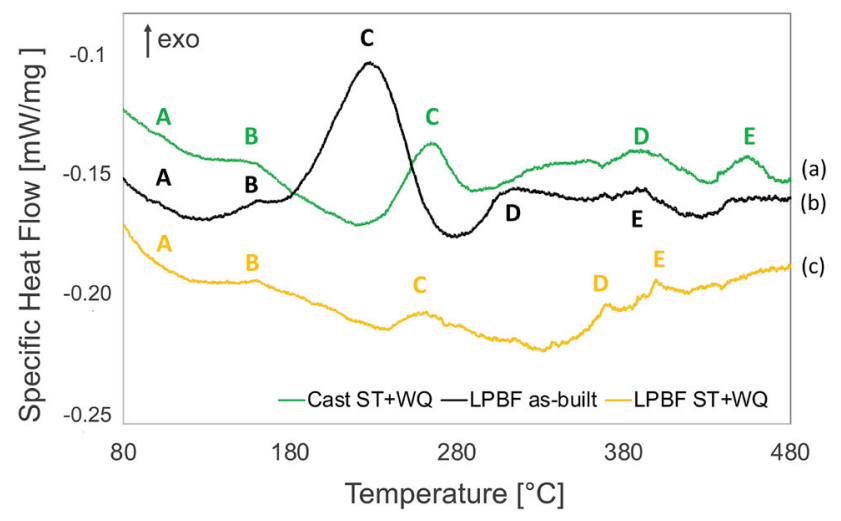

Fig. 4-DTA analyses of: (a) cast ST + WQ, (b) LPBF as-built, and (c) LPBF ST + WQ samples. Letters A, B, C, D, and E identify exothermic peaks.

Table IV. Onset and Peak Temperatures of A, B, C, and D Exothermic Reactions Identified by DTA Scans for Cast ST + WQ, LPBF As-built and LPBF ST + WQ Samples

\begin{tabular}{|c|c|c|c|c|c|c|c|c|}
\hline \multirow{2}{*}{ Sample } & \multicolumn{2}{|c|}{ Peak B } & \multicolumn{2}{|c|}{ Peak C } & \multicolumn{2}{|c|}{ Peak D } & \multicolumn{2}{|c|}{ Peak E } \\
\hline & $T_{\text {on }}\left({ }^{\circ} \mathrm{C}\right)$ & $T_{\mathrm{p}}\left({ }^{\circ} \mathrm{C}\right)$ & $T_{\text {on }}\left({ }^{\circ} \mathrm{C}\right)$ & $T_{\mathrm{p}}\left({ }^{\circ} \mathrm{C}\right)$ & $T_{\text {on }}\left({ }^{\circ} \mathrm{C}\right)$ & $T_{\mathrm{p}}\left({ }^{\circ} \mathrm{C}\right)$ & $T_{\text {on }}\left({ }^{\circ} \mathrm{C}\right)$ & $T_{\mathrm{p}}\left({ }^{\circ} \mathrm{C}\right)$ \\
\hline Cast ST + WQ & 143 & 161 & 249 & 257 & 370 & 394 & 435 & 456 \\
\hline LPBF As-built & 155 & 159 & 195 & 221 & 290 & 306 & 375 & 390 \\
\hline $\mathrm{LPBF} \mathrm{ST}+\mathrm{WQ}$ & 151 & 163 & 248 & 266 & 360 & 362 & 380 & 382 \\
\hline
\end{tabular}




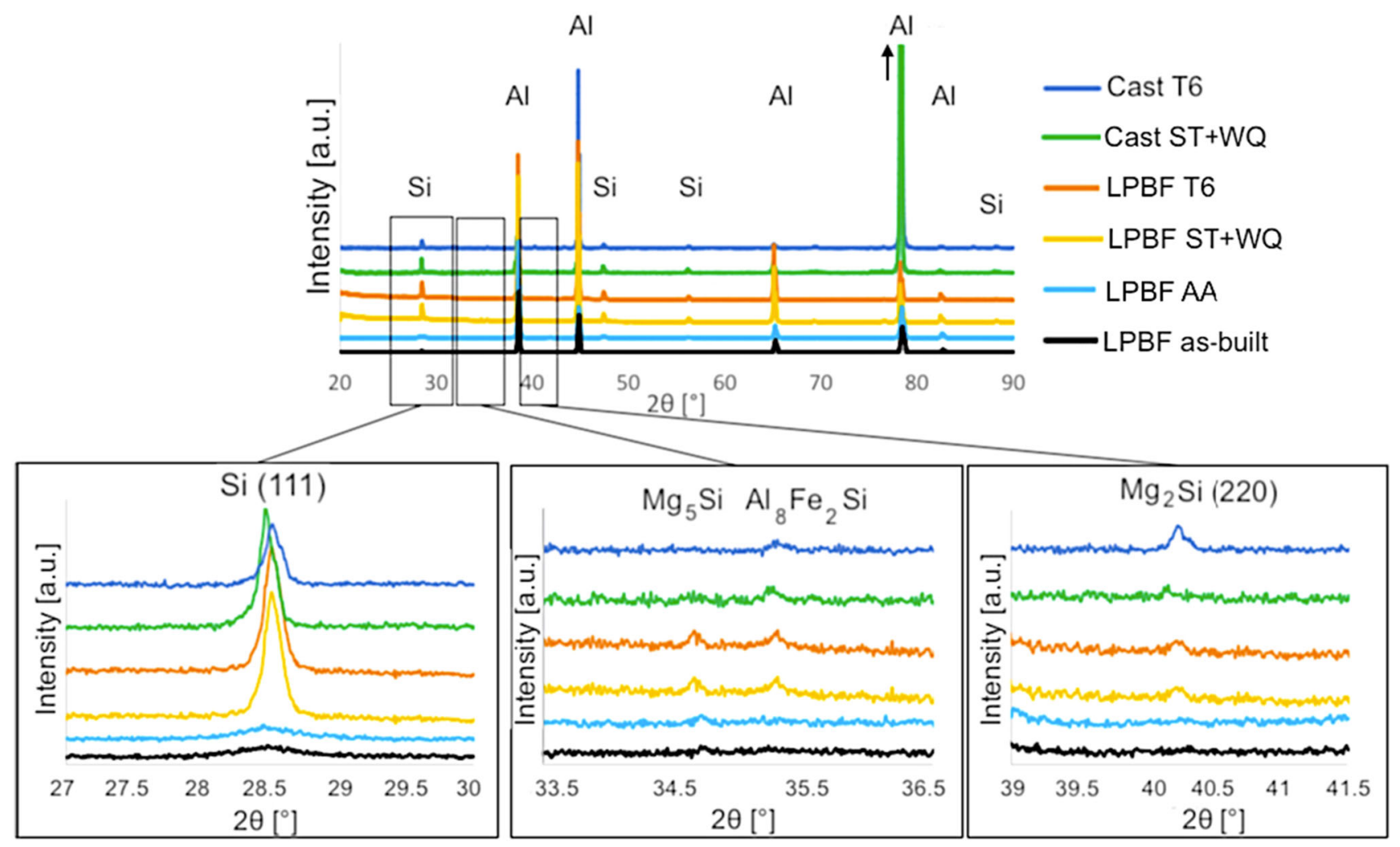

Fig. 5-XRD analyses of as-built, ST +WQ, and T6 peak-aged alloys: global view and details of lower peaks in the range 27 to $30,33.5$ to 36.5 , 39 to 41.5 deg.

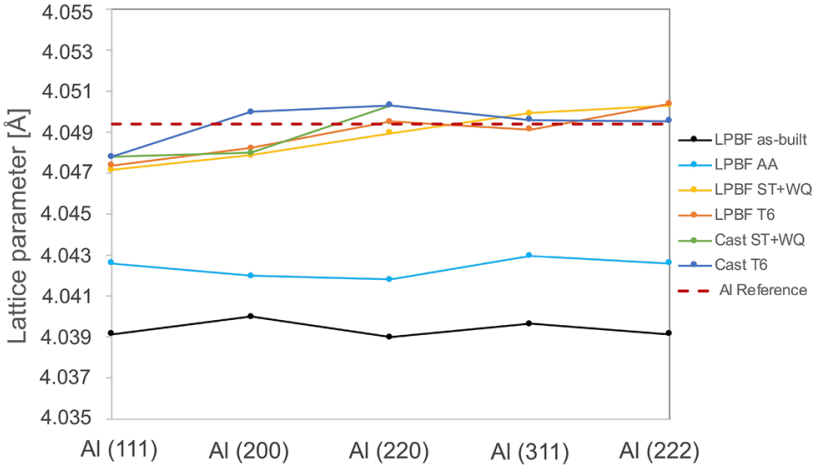

Fig. 6-Lattice parameter calculated for the aluminum phase as a function of lattice planes compared to the reference value.

discussed in more detail in the following sections. A comparison of the aging curves, corresponding to the peak aging conditions for all the investigated alloys (Cast ST + WQ, LPBF as-built and LPBF ST + WQ) is given in Figure 2(d). The comparison shows that, even in the peak-aged condition, the cast alloy returned to lower hardness values than those of LPBF. Moreover, even if the LPBF and cast alloy exhibited a comparable hardness value after $\mathrm{ST}+\mathrm{WQ}$, the strengthening induced by aging was enhanced in the LPBF alloy. A comparison of $\mathrm{HV}_{1}$ hardness values of all heat-treated samples, including the LPBF as-built ones subjected to stress relieving at $100{ }^{\circ} \mathrm{C}(\mathrm{SR} 100), 200{ }^{\circ} \mathrm{C}$ (SR200), and
$300{ }^{\circ} \mathrm{C}$ (SR300), is reported in Figure 3. The as-built LPBF samples had an average hardness of $117 \pm 2 \mathrm{HV}_{1}$ and were not affected by low-temperature $\left(100{ }^{\circ} \mathrm{C}\right) \mathrm{SR}$ treatment, while medium temperature $\left(200{ }^{\circ} \mathrm{C}\right)$ slightly increased the hardness, as also confirmed by the $210{ }^{\circ} \mathrm{C}$ aging curve (Figure 2(a)). High-temperature treatment such as SR at $300{ }^{\circ} \mathrm{C}$ and ST + WQ caused a significant hardness drop to approximately $80 \mathrm{HV}_{1}$, comparable to the ST + WQ cast alloy.

Thermal analyses (DTA) were conducted to investigate the different responses to aging treatment displayed in the aging curves. DTA curves obtained for the LPBF as-built alloy, the solution-treated and water-quenched $(\mathrm{ST}+\mathrm{WQ})$ LPBF alloy and the solution-treated and water-quenched (ST $+\mathrm{WQ}$ ) cast alloy are compared in Figure 4. Five exothermic peaks, identified by the letters A, B, C, D and E, could be recognized on the investigated samples, with the only exception of LPBF ST + WQ alloy for which peak A was not clearly identifiable. Exothermic peaks correspond to the phase precipitations and transformations occurring in the range $90{ }^{\circ} \mathrm{C}$ to $450{ }^{\circ} \mathrm{C}$. Most of the literature regarding the conventional cast alloy ${ }^{[29-32]}$ fixes the formation of GP zones at about $100^{\circ} \mathrm{C}$, thus corresponding to peak A. However, the attribution of the remaining peaks is debated in the literature. Several authors ${ }^{[29-31]}$ agree on the attribution of the peak at about $200{ }^{\circ} \mathrm{C}$ to $250{ }^{\circ} \mathrm{C}$ (peak C) to the precipitation of $\beta^{\prime \prime}$ coherent and strengthening phase, while peak D may correspond to both the $\beta^{\prime \prime}$ to $\beta^{\prime}$ transformation and the precipitation of 
$\mathrm{Si}$ and peak $\mathrm{E}$ to the final transformation into the equilibrium incoherent $\beta\left(\mathrm{Mg}_{2} \mathrm{Si}\right)$ phase. It should be noticed that none of the aforementioned references evidenced a peak in the range of $150{ }^{\circ} \mathrm{C}$ (termed $\mathrm{B}$ in Figure 4), which was indeed found on the DTA curves of all investigated samples. According to Reference 32, which investigated the AlSi7Mg cast alloy, the precipitation of $\beta^{\prime \prime}$ is anticipated at about $150^{\circ} \mathrm{C}$ and the peak in the range of $220^{\circ} \mathrm{C}$ to $250{ }^{\circ} \mathrm{C}(\mathrm{C})$ is attributed to the

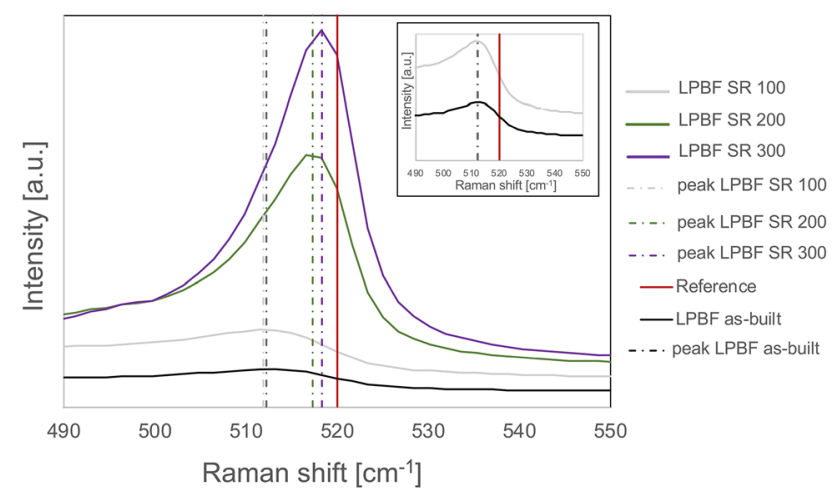

(a)

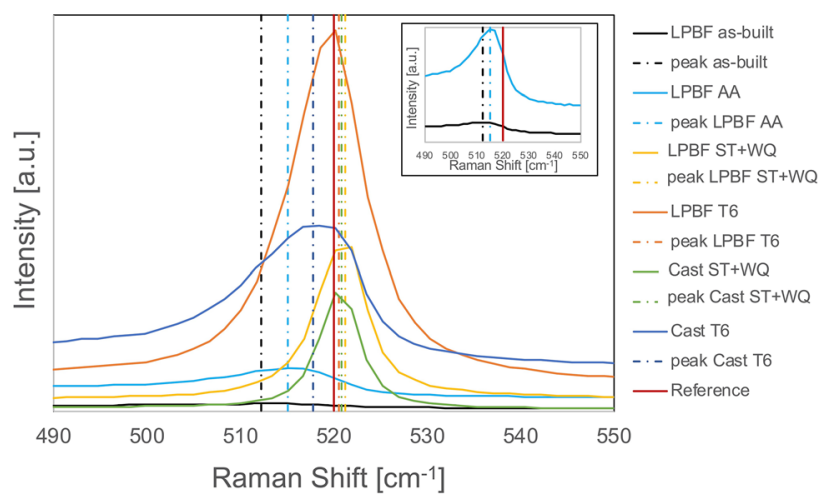

(b)

Fig. 7-Raman spectra of the Si frequency of heat-treated samples compared to the LPBF as-built sample: (a) stress-relieving treatments, and (b) ST + WQ and T6 conditions. In the insets, details of LPBF as-built, LPBF SR100, and LPBF AA are given. precipitation of $\beta^{\prime}$ while the following peak (D) to the precipitation of Si. In the case of the LPBF A357 alloy, Casati and Vedani ${ }^{[15]}$ associated peak $\mathrm{C}$ to the $\beta^{\prime \prime}$ phase, peak $\mathrm{D}$ to $\beta^{\prime}$ and the last one located close to $350^{\circ} \mathrm{C}(\mathrm{E})$ to $\mathrm{Si}$ precipitation. Moving to the $\mathrm{LPBF}$ AlSil0Mg alloy, which follows the same precipitation path as the AlSi7Mg alloy, Marola et al. ${ }^{[33]}$ attributed peak $\mathrm{C}$ to the precipitation of $\mathrm{Si}$ from the supersaturated solid solution and the peak $\mathrm{D}$ to the precipitation of $\mathrm{Mg}_{2} \mathrm{Si}$. For the same alloy, instead, Fiocchi and colleagues ${ }^{[34]}$ identified peak $\mathrm{C}$ as $\mathrm{Mg}_{2} \mathrm{Si}$ precipitation and the following peak $\mathrm{D}$ as the $\mathrm{Si}$ precipitation. Notably, in the present investigation peak $\mathrm{C}$ prevailed for all samples, and the area under that peak, which corresponds to the enthalpy of the transformation in case of LPBF as-built samples, is much higher compared to solutionized samples $\left(92.9 \mathrm{~J} \mathrm{~g}^{-1}\right.$ for LPBF as-built, 24.4 and $6.5 \mathrm{~J} \mathrm{~g}^{-1}$ for cast ST +WQ and LPBF ST +WQ, respectively). Considering the supersaturated condition obtained with the LPBF process, it could be inferred that the high enthalpy associated with peak $\mathrm{C}$ in the $\mathrm{LPBF}$ as-built alloy is related to the precipitation of $\mathrm{Si}$. Moreover, as also shown by the data reported in Table IV, except peaks A and B, all peaks in the LPBF as-built alloy are moved to lower temperatures with respect to both cast ad LPBF solutionized alloy.

Phase composition of solutionized and peak-aged samples can be deduced by the analysis of XRD spectra reported in Figure 5, where all heat-treated samples are compared to the LPBF as-built one. Major peaks identified for all samples belong to Al (ICDD: 4-0787) and Si (ICDD: 27-1402) phases. Notice that in case of cast samples a preferred crystallographic orientation was shown by the prevalence of $\mathrm{Al}(200)$ at $44.7 \mathrm{deg}$ and Al (222) at 82.4 deg peaks. Since cast samples were extracted from an engine block, this is presumably related to the specific region of sample extraction. Therefore, for the sake of proper comparison, the XRD spectra of cast samples were acquired on samples extracted from the same area. A detail of the most intense $\mathrm{Si}$ peak $(\mathrm{Si}(111))$ is given in the inset, which shows that in LPBF as-built and direct-aged (AA) samples the peak was almost negligible while after solution treatment, as well as in cast samples, was well

Table V. Average Raman Shift of the Si Peak Measured for All Investigated Samples Compared With the Reference Value for Unstressed $\mathrm{Si}^{|34-36|}$

\begin{tabular}{llr}
\hline Sample & \multicolumn{1}{c}{ Condition } & Si Raman Shift $\left(\mathrm{cm}^{-1}\right)$ \\
\hline LPBF As-built & as-built & $512.2 \pm 0.9$ \\
LPBF SR100 & SR $\left(100^{\circ} \mathrm{C} \times 120 \mathrm{~min}\right)$ & $511.9 \pm 0.8$ \\
LPBF SR200 & $\mathrm{SR}\left(200^{\circ} \mathrm{C} \times 120 \mathrm{~min}\right)$ & $517.3 \pm 0.9$ \\
LPBF SR300 & $\mathrm{SR}\left(300^{\circ} \mathrm{C} \times 120 \mathrm{~min}\right)$ & $518.3 \pm 0.1$ \\
LPBF ST+WQ & $\mathrm{ST}\left(540^{\circ} \mathrm{C} \times 10 \mathrm{~min}\right)+\mathrm{WQ}$ & $521.2 \pm 1.5$ \\
LPBF T6 (Peak-Aged) & $\mathrm{ST}+\mathrm{WQ}+\mathrm{AA}\left(150^{\circ} \mathrm{C} \times 4 \mathrm{~h}\right)$ & $520.5 \pm 0.8$ \\
LPBF AA (Peak-Aged) & $\mathrm{AA}\left(170^{\circ} \mathrm{C} \times 1 \mathrm{~h}\right)$ & $515.1 \pm 0.1$ \\
& $\mathrm{AA}\left(170^{\circ} \mathrm{C} \times 4 \mathrm{~h}\right)$ & $514.1 \pm 0.9$ \\
Cast ST + WQ & $\mathrm{ST}\left(540^{\circ} \mathrm{C} \times 720 \mathrm{~min}\right)+\mathrm{WQ}$ & $520.8 \pm 0.9$ \\
Cast T6 (Peak-Aged) & $\mathrm{ST}+\mathrm{WQ}+\mathrm{AA}\left(190{ }^{\circ} \mathrm{C} \times 4 \mathrm{~h}\right)$ & $517.8 \pm 2.3$ \\
Reference & & 520 \\
\hline
\end{tabular}



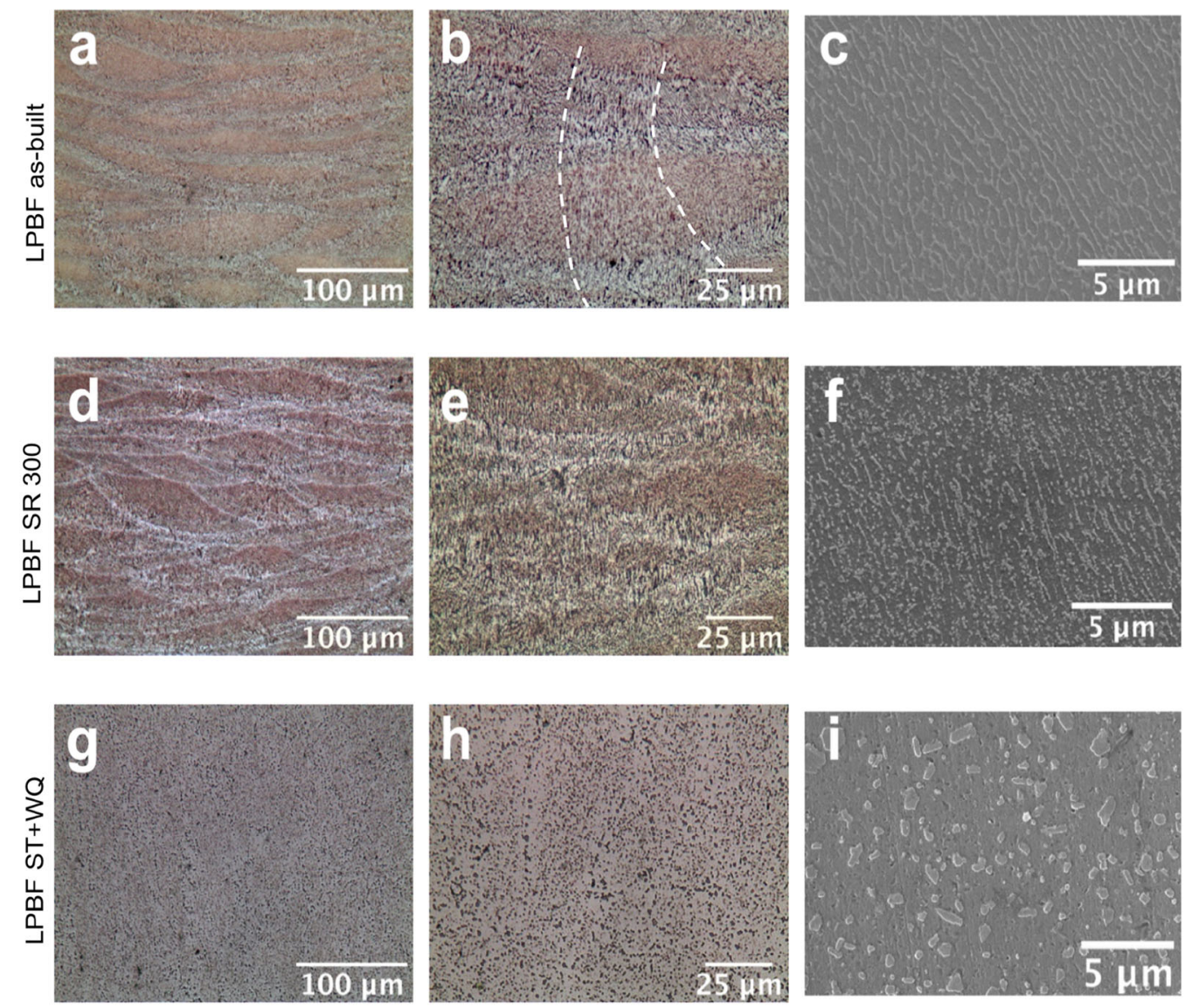

Fig. 8-Metallographic analyses of LPBF as-built, SR300, and ST +WQ samples: $(a, d, g)$ low-magnification optical images, $(b, e, h)$ high-magnification optical micrographs, and $(c, f, i)$ SEM analyses. White dashed line outlines an epitaxial grain crossing-over layer.

defined. The integrated area of the peak for LPBF and cast alloys after ST + WQ and T6 treatments was analogous. By comparing the ratio of the integrated area of the Si (111) and $\mathrm{Al}$ (111) peaks for the LPBF alloys, similar values were observed in case of ST + WQ and T6 alloys. A comparable $\mathrm{Si}(111) / \mathrm{Al}(111)$ ratio was also found among AA and as-built alloys. This outcome confirms that precipitation of $\mathrm{Si}$ from the $\mathrm{Al}$ matrix occurred after the 10 minutes solution treatment. Low peaks in the range of 35 to $40 \mathrm{deg}$ can be attributed to $\mathrm{Mg}_{5} \mathrm{Si}_{6}$ phase (ICDD: 1-088-1207), $\mathrm{Al}_{8} \mathrm{Fe}_{2} \mathrm{Si}$ intermetallic phase (ICDD: 20-0030), and $\mathrm{Mg}_{2} \mathrm{Si}$ (ICDD: 35-0773). In case of $\mathrm{Mg}_{2} \mathrm{Si}$, the peak located at approximately 40 deg is the most intense one and was chosen to compare the occurrence of precipitation among samples. For the LPBF alloy, peaks corresponding to $\mathrm{Mg}_{2} \mathrm{Si}$ and Fe-based intermetallics became appreciable only after solution treatment, while the peak attributed to $\mathrm{Mg}_{5} \mathrm{Si}_{6}$ was much less prominent in the cast alloy, especially after T6 treatment. Literature results of the LPBF AlSi7Mg0.6 alloy subjected to short ( 1 to 2 hours) solution treatment showed, indeed, that coarsening of intermetallic particles might occur, which became visible as acicular particles at both optical and scanning electron analyses. ${ }^{[15,16]}$ The lattice parameter of the face-centered cubic aluminum structure was calculated from XRD spectra, and the results are reported in Figure 6 as a function of the lattice planes. The reference value for the lattice parameter of $\mathrm{Al}$ is $4.0494 \AA$ (ICDD: 4-0787). LPBF samples in as-built and artificially aged conditions exhibited significantly lower lattice parameters, which were quite stable for all lattice planes. Cast and LPBF samples in T6 and ST + WQ state instead displayed comparable lattice parameters that increased to values close to the nominal one. Since the atomic radius of $\mathrm{Si}$ is lower than that of $\mathrm{Al}$, a compressed aluminum lattice implies that a large part of $\mathrm{Si}$ is retained in the solid solution in LPBF as-built alloy. Results also suggest that some of the retained $\mathrm{Si}$ was released after the direct aging treatment, and it was almost completely ejected after solution treatment and quenching. Similar results for the $\mathrm{Al}-\mathrm{Si}-\mathrm{Mg}$ alloys produced by LPBF were also reported by other authors. ${ }^{[33,35]}$ In particular, according to Rao et al. ${ }^{[35]}$ $\mathrm{Si}$ super-solubility is strictly related to the crystallographic-dependent residual strain in the Al matrix; thus, a possible way to reduce the strain is to induce the precipitation of Si-rich particles. 

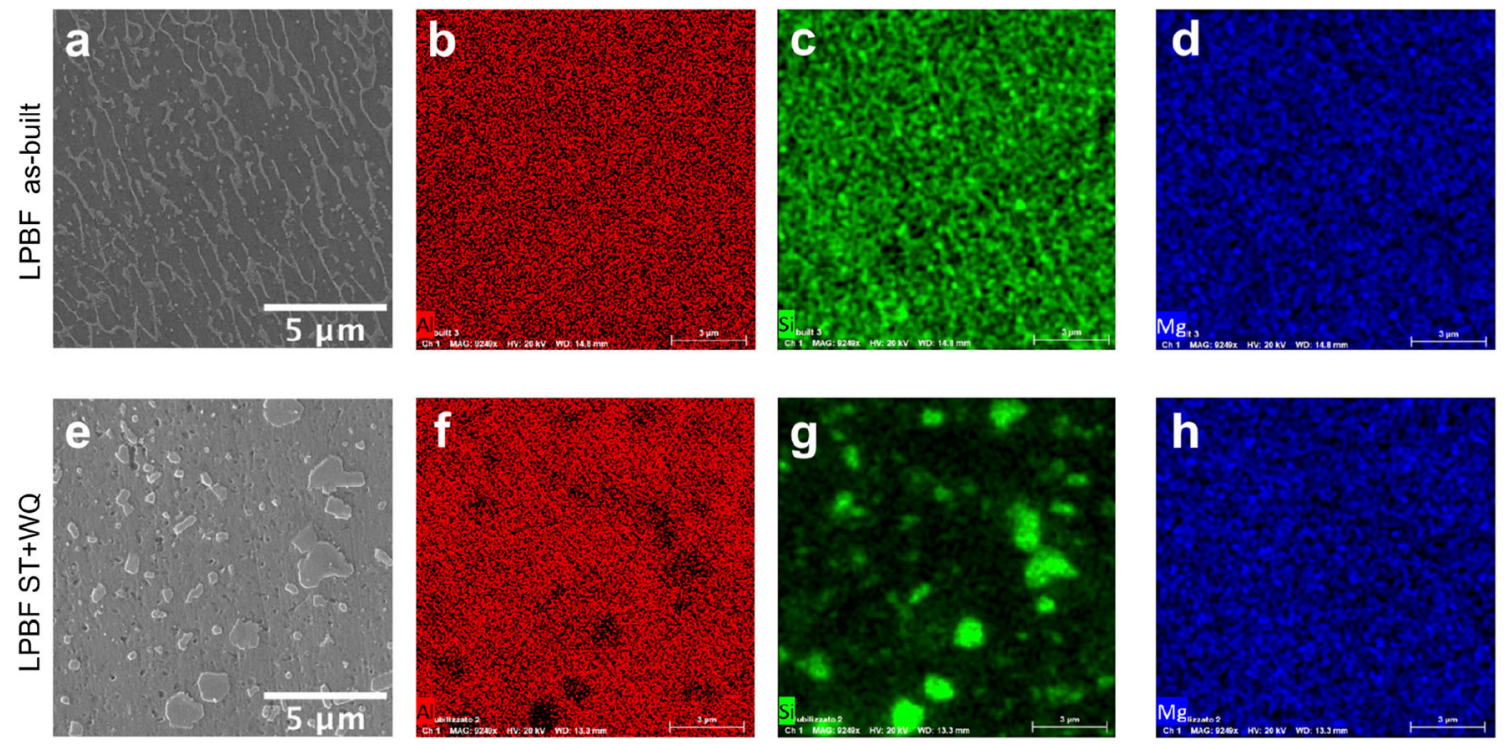

Fig. 9-FEG-SEM EDS maps of as-built $(a)$ and ST + WQ $(e)$ LPBF samples showing concentrations of: $(b$ and $f)$ aluminum, $(c$ and $g)$ silicon, $(d$ and $h)$ magnesium.

\section{B. Residual Stress}

The evaluation of residual stress was performed via Raman analysis by the characterization of the frequency of Si. In fact, while aluminum is not a Raman active material, the unstressed Si displays a Raman frequency at $520 \mathrm{~cm}^{-1} \cdot{ }^{[36-38]}$ Since mechanical stress can shift the peak to lower values (in case of tensile stress) and higher values (in case of compressive stress), ${ }^{[39]}$ Raman spectroscopy is commonly used to determine residual stress in different Si-based components. ${ }^{[26-28]}$ Therefore, Raman spectra were collected for cast and LPBF heat-treated samples and, as a reference, results were compared to the LPBF as-built condition and to the reference value of unstressed Si (Figure 7). In addition, for ease of comparison, numerical values of the average Si peak obtained for all samples are reported in Table V. In the LPBF as-built alloy, the Si-peak is located to a significantly lower value (approximately $512 \mathrm{~cm}^{-1}$ ) than the reference, suggesting a residual tensile stress state. As a first assessment, the effect of conventional stress-relieving treatment was analyzed (Figure 7(a)), performed for a fixed soaking time ( 2 hours) at different temperatures $\left(100{ }^{\circ} \mathrm{C}, 200^{\circ} \mathrm{C}, 300{ }^{\circ} \mathrm{C}\right)$. Results showed that the SR performed at $100{ }^{\circ} \mathrm{C}$ (SR 100) affected neither the internal stress state nor the alloy hardness (Figure 3). SR200 and SR300 instead succeeded in reducing part of the residual stress, since the Si-peak increased up to about $518 \mathrm{~cm}^{-1}$. The effect of strengthening heat treatments is displayed in Figure 7(b). The 1-hour artificial aging of the LPBF as-built alloy had little effect on reducing tensile stress; hence, a longer soaking time was considered. Indeed, according to the aging curve reported in Figure 2(a), the peak hardness was maintained for even longer treatment; therefore, aiming to induce more significant relieving of residual stress, artificial aging treatment at $170^{\circ} \mathrm{C} \times 4$ hours was performed. However, as Table $\mathrm{V}$ shows, both AA treatments resulted in a comparable value of Raman frequency of $\mathrm{Si}$, settling at about $515 \mathrm{~cm}^{-1}$. Conversely, solution treatment was able to completely release all the residual tensile stress since the measured shift of the $\mathrm{Si}$ is about $521 \mathrm{~cm}^{-1}$. This outcome was shown for both LPBF and conventional cast alloy. Finally, the complete T6 treatment for the LPBF alloy produced a complete relaxation of residual stress since the $\mathrm{Si}$ peak corresponded to the unstressed reference value of $520 \mathrm{~cm}^{-1}$. On the other hand, for the cast T6 alloy, the measured value of about $518 \mathrm{~cm}^{-1}$ suggests a residual tensile stress state. By recalling the analyses on the $\mathrm{Al}$ lattice parameter in Figure 6, a similar trend was already shown by XRD analyses. In fact, only after the complete T6 treatment the LPBF alloy was characterized by a lattice parameter close to the cast samples and reference value.

\section{Metallographic Analyses}

Metallographic analyses carried out on LPBF samples are reported in Figure 8, where stress-relieved (SR300) and solution-treated (ST $+\mathrm{WQ})$ microstructures are compared to the as-built one. As widely reported in the literature, ${ }^{[4,40]}$ as-built alloy is dominated by a hierarchical microstructure that comprises a layered structure due to subsequent solidified melt pools, resolved at low-magnification optical analyses (Figure 8(a)), and epitaxial grain crossing-over layers and a cellular microstructure inside melt pools that can be appreciated only at higher magnifications (Figures 8(b) and (c)). In optical microscopy, melt pool borders can be identified by a light-colored area where the cellular structure is coarser because of subsequent re-heating during the process. At the center of melt pools, instead, a finer cellular structure can be found. This cellular structure is composed of a fine and continuous network of eutectic Si surrounding the Al- $\alpha$ phase (Figure 8(c)). During the extremely rapid solidification imposed by 
LPBF, epitaxial growth of the primary Al- $\alpha$ phase occurs, and, as a consequence, columnar grain crossing-over layers can be appreciated in high-magnification optical analyses (Figure 8(b)), outlined by a white dashed line. By exposing the alloy to heating at $300{ }^{\circ} \mathrm{C}$ for a holding time of 2 hours (SR300 treatment), coarsening of the microstructure occurred even though the layered structure and melt pool border could still be appreciated by optical analyses (Figures 8(d) and (e)). SEM microscopy (Figure $8(\mathrm{f})$ ) revealed an interrupted $\mathrm{Si}$ network and the coalescence of small globular $\mathrm{Si}$ particles. A soaking time of only 10 minutes at solution temperature $\left(540{ }^{\circ} \mathrm{C}\right)$ resulted in a significant change in the microstructure. Melt pool borders were no longer appreciable (Figures $8(\mathrm{~g})$ and $(\mathrm{h})$ ), the fine Si-rich network broke up, and globular particles were formed (Figure 8(i)). Because of the short exposition at high temperature, these globular particles were very small in size: few of them are in the range of 1 to $2 \mu \mathrm{m}$ but most have a size $<1 \mu \mathrm{m}$, as already shown by the results in Figure 1. FEG-SEM EDS maps were made to evaluate the distribution of the alloy elements in the in the as-built samples and after solution treatment (Figure 9). While in the LPBF as-built alloy the instrument could not highlight differences in the distribution of the alloy elements, possibly due to the supersaturation of the solid solution, after solution treatment $\mathrm{Si}$ segregated into the above-mentioned globular particles.

\section{DISCUSSION}

Results confirmed that the LPBF A357 alloy in the as-built condition has the potential to respond to artificial aging (AA) treatment. Aging curves (Figure 2), in fact, showed an increase in hardness for brief (up to 2 hours) treatments at all investigated temperatures, and the peak-aging condition was reached after 1-hour treatment performed at $170{ }^{\circ} \mathrm{C}$. The aging response of the LPBF ST + WQ alloy was different, showing a marked influence of treatment temperature. Peak aging condition (T6) was obtained for the lowest temperature $\left(150{ }^{\circ} \mathrm{C}\right)$ and a holding time of 4 hours. It should be noticed that, even if $\mathrm{AA}$ and $\mathrm{T} 6$ treatment reached similar hardness values (136 and $130 \mathrm{HV}_{1}$ respectively), if compared to the hardness before aging, T6 displayed a 60 pct increase, while AA only 17 pct, thus suggesting that different phenomena were involved. According to the findings of Rao et al., ${ }^{[41]}$ who performed TEM analyses on direct aged and T6 A357 alloy, direct aging of the LPBF as-built alloy resulted in precipitation of randomly oriented $\mathrm{Si}$ nano-particles, because of the higher supersaturation of $\mathrm{Si}$, with respect to $\mathrm{Mg}$, of the as-built alloy. On the other hand, in the solutionized alloy at peak-aged condition, both $\beta^{\prime \prime}$ and $\beta^{\prime}$ could be found. In the present study, precipitation of $\mathrm{Si}$ was shown by the analysis of the lattice parameter (Figure 6): the increase in the lattice parameter found after direct aging (AA) of the as-built LPBF alloy suggested a release of $\mathrm{Si}$ atoms from the solid solution. However, phase composition analyses (XRD, Figure 5) did not show a marked increase in the $\mathrm{Si}$ (111) peak after AA, thus suggesting that most of the $\mathrm{Si}$ was still retained in the Al matrix. XRD analyses also showed that for the LPBF alloy, after solution treatment, the Si (111) peak became clearly visible and comparable to the cast alloys, proving that precipitation of $\mathrm{Si}$ from the matrix occurred. Further evidence of the occurrence of $\mathrm{Si}$ precipitation is represented by the increase in the lattice parameter, which reached comparable values for solutionized LPBF and cast alloys. Indeed, the main difference highlighted by thermal analyses (Figure 4) between as-built and solutionized samples was represented by peak $\mathrm{C}$, followed by $\mathrm{D}$ and $\mathrm{E}$ peaks. Based on the above, in accordance with Marola et al., ${ }^{[33]}$ it is plausible to attribute the main exothermic peak (C) found on DTA scans (Figure 4) to the precipitation of $\mathrm{Si}$ from the supersaturated matrix, being predominant for the as-built alloy and much less intense in case of ST + WQ alloy where the precipitation of Si has already occurred. Consequently, the following peak (D) can be attributed to the $\mathrm{Mg}_{2} \mathrm{Si}$ precipitation. Furthermore, only after ST $+\mathrm{WQ}$ could the peak of the $\mathrm{Mg}_{2} \mathrm{Si}$ phase be detected in XRD spectra (Figure 5) where the $\mathrm{Mg}_{2} \mathrm{Si}$ peak was observed only in the LPBF ST +WQ alloy. However, all XRD spectra of LPBF samples showed a small peak in the range of $2 \theta=34.7 \mathrm{deg}$ while the same was not detected on the cast alloy. The presence of this peak, attributed to the $\beta^{\prime \prime}\left(\mathrm{Mg}_{5} \mathrm{Si}_{6}\right)$ phase, is independent from the heat treatment condition, and thus it seems mainly related to the LPBF process; for this reason, it was not further investigated in the present work. Moving to residual stress analyses (Table V), it is worth noticing that even if AA succeeded in releasing part of it, higher temperatures $\left(>300{ }^{\circ} \mathrm{C}\right)$ were required to completely relieve the residual stress that characterizes the LPBF as-built alloy. In particular, the results showed that a short (10 minutes) solution treatment followed by water quenching is sufficient to obtain a residual stress state comparable to both the un-stressed reference and the cast alloy. The conventional stress-relieving treatment applied to the LPBF alloy (SR300) was capable of relieving most of the residual stress condition, but the hardness of the alloy dropped to $84 \mathrm{HV}_{1}$ (from $117 \mathrm{HV}_{1}$ of the as-built condition, Figure 3). This outcome can be partially explained based on the microstructural analyses (Figure 7), which showed coarsening of the microstructure with respect to the as-built condition. The LPBF as-built alloy was characterized by an extremely fine microstructure comprised of $\alpha$-Al cells surrounded by a fine network of eutectic Si. The exposure of such microstructure at $300{ }^{\circ} \mathrm{C}$ for 2 hours caused the partial break of the Si network and coarsening of $\mathrm{Si}$ particles located inside the cells. Otherwise, solution treatment caused deep changes in the microstructure: complete break of the Si network occurred and globular Si-rich particles formed. In addition, any trace of the layered structure or subsequent melt pools disappeared. Nevertheless, because of the shortened (10 minutes) high-temperature exposure, $\mathrm{Si}$ particles were mostly sub-micrometer sized. In addition, the shorten solution treatment presumably hindered the coarsening of intermetallic particles, observed by other authors who performed longer 
treatments. ${ }^{[15,16]}$ In fact, even if XRD spectra (Figure 5) revealed the LPBF alloy and, after solution treatment, a peak consistent with $\mathrm{Al}-\mathrm{Fe}-\mathrm{Si}$ intermetallic compounds, the presence of Fe-based particles was not evidenced by microstructural analyses (Figures 8 and 9).

\section{CONCLUSIONS}

The present work was focused on assessing the role of heat treatment on the microstructure, hardness and residual stress of the $\mathrm{A} 357$ (A1Si7Mg0.6) alloy produced by laser powder bed fusion (LPBF). Stress relieving, direct aging and complete T6 treatment were investigated and, as a reference, also the conventional sand-cast alloy was considered. Based on the results, the following conclusions can be deduced:

- Stress-relieving treatment applied to the LPBF asbuilt alloy produced a drop in the hardness value, but was not sufficient to completely release residual stress.

- Direct aging of LPBF as-built alloy resulted in strengthening the alloy and also succeeded in a partial relief of residual stress.

- The optimized T6 treatment was able to return hardness values comparable to the direct aging treatment but it succeeded also in completely relieving residual stress.

- With respect to the conventional cast A357 T6 alloy, both treatments resulted in higher hardness values in the peak-aging condition.

- Microstructural results suggested that, because of the supersaturated solid solution derived from the LPBF process, different precipitation phenomena were involved in direct aging and T6 treatments of the LPBF alloy.

\section{ACKNOWLEDGMENTS}

The authors thank Dr. Iuri Boromei at the University of Bologna for his valuable contribution to the FEG-SEM-EDS, DTA, and XRD analyses and Ms. Greta Ponzoni for the support of the experimental work. This research did not receive any specific grant from funding agencies in the public, commercial, or not-for-profit sectors.

\section{FUNDING}

Open access funding provided by Alma Mater Studiorum-Università di Bologna within the CRUICARE Agreement.

CONFLICT OF INTEREST All authors declare that they no conflict of interest or financial ties to disclose.

\section{OPEN ACCESS}

This article is licensed under a Creative Commons Attribution 4.0 International License, which permits use, sharing, adaptation, distribution and reproduction in any medium or format, as long as you give appropriate credit to the original author(s) and the source, provide a link to the Creative Commons licence, and indicate if changes were made. The images or other third party material in this article are included in the article's Creative Commons licence, unless indicated otherwise in a credit line to the material. If material is not included in the article's Creative Commons licence and your intended use is not permitted by statutory regulation or exceeds the permitted use, you will need to obtain permission directly from the copyright holder. To view a copy of this licence, visit http://creat ivecommons.org/licenses/by/4.0/.

\section{REFERENCES}

1. M. Javidani and D. Larouche: Int. Mater. Rev., 2014, vol. 59, pp. 132-58. https://doi.org/10.1179/1743280413Y.0000000027.

2. B. Stojanovic, M. Bukvic, and I. Epler: Appl. Eng. Lett. J. Eng. Appl. Sci., 2018, vol. 3, pp. 52-62. https://doi.org/10.18485/aeletters.2018.3.2.2.

3. T. DebRoy, H.L. Wei, J.S. Zuback, T. Mukherjee, J.W. Elmer, J.O. Milewski, A.M. Beese, A. Wilson-Heid, A. De, and W. Zhang: Prog. Mater. Sci., 2018, vol. 92, pp. 112-24. https:// doi.org/10.1016/j.pmatsci.2017.10.001

4. J. Zhang, B. Song, Q. Wei, D. Bourell, and Y. Shi: J. Mater. Sci. Technol, 2019, vol. 35, pp. 270-84. https://doi.org/10.1016/ j.jmst.2018.09.004.

5. G. Sigworth: Aluminum Science and Technology-ASM Handbook, ASM International, Materials Park, 2018, vol. 2A, pp. 165-74. 10.31399/asm.hb.v02a.a0006496.

6. L. Ceschini, A. Morri, A. Morri, and G. Pivetti: Mater. Des., 2011, vol. 32, pp. 1367-75. https://doi.org/10.1016/j.matdes.2010.09. 014.

7. L. Ceschini, A. Morri, A. Morri, A. Gamberini, and S. Messieri: Mater. Des., 2009, vol. 30, pp. 4525-31. https://doi.org/10.1016/ j.matdes.2009.05.012.

8. J.G. Kaufman: Introduction to Aluminum Alloys and Tempers, ASM International, Materials Park, 2000, pp. 9-22. 10.1361/ iaat2000p009.

9. L. Katgerman and D. Eskin: in Handbook of Aluminum, GE Totten, ed., CRC Press, Boca Raton, 2003, vol. 1, pp. 278-80.

10. ASTM International: ASTM B. Stand. (2012). https://doi.org/10. 1520/B0917.

11. A. Morri, L. Ceschini, S. Messieri, E. Cerri, and S. Toschi: Metals (Basel), 2018, https://doi.org/10.3390/met8060393.

12. J.H. Rao, Y. Zhang, X. Fang, Y. Chen, X. Wu, and C.H.J. Davies: Addit. Manuf., 2017, vol. 17, pp. 113-22. https://doi.org/ 10.1016/j.addma.2017.08.007.

13. F. Trevisan, F. Calignano, M. Lorusso, J. Pakkanen, E.P. Ambrosio, L. Mariangela, M. Pavese, D. Manfredi, and P. Fino: World PM 2016 Congr. Exhib..

14. J.C. Pereira, E. Gil, L. Solaberrieta, M. San Sebastián, Y. Bilbao, and P.P. Rodríguez: Mater. Sci. Eng. A, 2020, vol. 778, p. 139124. https://doi.org/10.1016/j.msea.2020.139124.

15. R. Casati and M. Vedani: Adv. Eng. Mater., 2019, vol. 21, p. 1800406. https://doi.org/10.1002/adem.201800406.

16. A. Mauduit, H. Gransac, P. Auguste, S. Pillot, and A. Diószegi: $J$. Cast. Mater. Eng., 2019, vol. 3, p. 1. https://doi.org/10.7494/ jcme.2019.3.1.1.

17. J.T. Oliveira de Menezes, E.M. Castrodeza, and R. Casati: Mater. Sci. Eng. A, 2019, vol. 766, p. 138392. https://doi.org/10.1016/ j.msea.2019.138392.

18. P. Van Cauwenbergh, A. Beckers, L. Thijs, B. Van Hooreweder, and K. Vanmeensel: Euro PM 2018 Congr. Exhib. 2020, pp. 1-7.

19. M. Wang, B. Song, Q. Wei, Y. Zhang, and Y. Shi: Mater. Sci. Eng. A, 2019, vol. 739, pp. 463-72. https://doi.org/10.1016/ j.msea.2018.10.047.

20. R. Casati, M.H. Nasab, M. Coduri, V. Tirelli, and M. Vedani: Metals (Basel), 2018, vol. 8, p. 954. https://doi.org/10.3390/ met8110954. 
21. L. Tonelli, E. Liverani, G. Valli, A. Fortunato, and L. Ceschini: Int. J. Adv. Manuf. Technol., 2020, vol. 106, pp. 371-83. https:// doi.org/10.1007/s00170-019-04641-x.

22. L. Ceschini, A. Morri, and A. Morri: J. Mater. Eng. Perform., 2013, vol. 22, pp. 200-05. https://doi.org/10.1007/s11665-0120208-1.

23. R. Lumley, R. O'Donnell, D. Gunasegaram, and M. Givord: Metall. Mater. Trans. A, 2007, vol. 38A, pp. 2564-74. https:// doi.org/10.1007/s11661-007-9285-4.

24. R.N. Lumey, I.J. Polmear, and P.R. Curtis: Metall. Mater. Trans. A, 2009, vol. 40A, pp. 1716-26. https://doi.org/10.1007/s11661009-9836-y.

25. F. Vander Voort: ASM Handbook-Metallography and Microstructures, ASM International, Materials Park, 2004, vol. 9. 10.31399/asm.hb.v09.9781627081771.

26. T. Menold, E. Hadjixenophontos, R. Lawitzki, G Schmitz, and M. Ametowobla: J. Appl. Phys., 2020, https://doi.org/10.1063/ 1.5142676.

27. C. Song, L. Du, L. Qi, Y. Li, X. Li, and Y. Li: J. Micromech. Microeng., 2017, https://doi.org/10.1088/1361-6439/aa8912.

28. B. Matthey, T. Pirling, M. Herrmann, and J. Schreiber: J. Eur. Ceram. Soc., 2020, vol. 40, pp. 1035-42. https://doi.org/10.1016/ j.jeurceramsoc.2019.11.055.

29. Q.G. Wang and C.J. Davidson: J. Mater. Sci., 2001, vol. 36, pp. 739-50.

30. R. Chen, Q. Xu, H. Guo, Z. Xia, Q. Wu, and B. Liu: Mater. Sci. Eng. A, 2017, vol. 685, pp. 391-402. https://doi.org/10.1016/ j.msea.2016.12.051.

31. C. Garcia-Cordovilla and E. Lousi: in Analytical Characterization of Aluminum, Steel, and Superalloys, DS MacKenzie and GE Totten, eds., CRC Press, Boca Raton, 2006, 1st Ed., pp. 293-338.
32. M. Massazza, G. Riontino, C. Riontino, A. Triggiani, and E. Carà: Mater. Sci. Forum, 2002, vols. 396-402, pp. 965-70. https:// doi.org/10.4028/www.scientific.net/MSF.396-402.965.

33. S. Marola, D. Manfredi, G. Fiore, M.G. Poletti, M. Lombardi, P. Fino, and L. Battezzati: J. Alloys Compd., 2018, vol. 742, pp. 27179. https://doi.org/10.1016/j.jallcom.2018.01.309.

34. C.A. Biffi, J. Fiocchi, and A. Tuissi: J. Alloys Compd., 2018, vol. 755, pp. 100-07. https://doi.org/10.1016/j.jallcom.2018.04.298.

35. J.H. Rao, Y. Zhang, K. Zhang, X. Wu, and A. Huang: Mater. Des., 2019, vol. 182, p. 108005. https://doi.org/10.1016/ j.matdes.2019.108005.

36. J.H. Parker, D.W. Feldman, and M. Ashkin: Phys. Rev., 1967, vol. 155, pp. 712-14. https://doi.org/10.1103/PhysRev.155.712.

37. P.A. Temple and C.E. Hathaway: Phys. Rev. B, 1973, vol. 7, pp. 3685-97. https://doi.org/10.1103/PhysRevB.7.3685.

38. K. Uchinokura, T. Sekine, and E. Matsuura: Solid State Commun., 1972, vol. 11, pp. 47-49. https://doi.org/10.1016/00381098(72)91127-1.

39. G. Sarau, A. Bochmann, R. Lewandowska, and S. Christianse: Advanced Aspects of Spectroscopy, InTech, London, 2012, pp. 221-46. $10.5772 / 48143$.

40. N.T. Aboulkhair, N.M. Everitt, I. Maskery, I. Ashcroft, and C. Tuck: MRS Bull., 2017, vol. 42, pp. 311-19. https://doi.org/ $10.1557 / \mathrm{mrs} .2017 .63$.

41. J.H. Rao, Y. Zhang, K. Zhang, A. Huang, C.H.J. Davies, and X. Wu: Scripta Mater., 2019, vol. 160, pp. 66-69. https://doi.org/ 10.1016/j.scriptamat.2018.09.045.

Publisher's Note Springer Nature remains neutral with regard to jurisdictional claims in published maps and institutional affiliations. 